faz com que os contextos sejam omitidos e que se presuma a ocorrência de paralelismos ocasionais, onde na realidade, trata-se de uma troca.

Esse esboço dos caminhos para a aproximação jurídica autônoma - a coope- ração espontânea, testada e aprovada, a recepção reiterada em vários países e o paralelismo evidente - demonstra um certo desenvolvimento em nível internacional, no qual também se insere a recepção do direito da Comunidade Européia nos Estados-membros do EFTA $^{(*)}$.

\title{
A Disciplina do Direito de Recesso no Projeto de Reforma da Lei das Sociedades Anônimas
}

\section{Paulo Lucena de ONeneres}

Advogado em São Paulo, sócio da Advocacia Gandra Martins

\section{Introdução ${ }^{1}$}

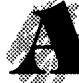

Lei $\mathrm{n}^{\mathrm{o}}$ 6.404/76, que disciplina o regime jurídico das sociedades por ações, surgiu em um contexto particular, quando se buscavam novas soluções para o desenvolvimento do País.

O referido diploma, como é notório, veio na esteira de uma profunda reforma legislativa, que teve início na década de 60 e resultou no delineamento de tópicos estruturais do ordenamento jurídico pátrio, como é o caso, entre outros, do sistema financeiro (Lei no ${ }^{\circ}$ 4.505/64) e tributário (Lei $\mathrm{n}^{\mathrm{O}} 5.172 / 66$ ), bem como da disciplina aplicável ao capital estrangeiro (Lei $n$ o 4.131/ 62). No entanto, como não poderia deixar de ser, na elaboração do texto legal foram adotados diversos paradigmas, que, por apresentarem opções políticas bastante nítidas, terminaram por causar grande polêmica à época.
Passados exatos vinte anos, constata-se que o diploma encontra-se em vias de ser alterado, com o objetivo de adaptá-lo a uma nova realidade. A passagem do tempo, contudo, não colocou este processo de revisão a salvo de contestações, mas, ao invés, reacendeu discussọ̃es sobre aspectos extremamente relevantes.

Em um primeiro plano, observa-se que a própria necessidade e conveniência de se alterar o diploma em vigor são, no momento, discutíveis.

Com efeito, além dos temores que cercam qualquer proposta legislativa que tenha por objeto a alteração de um relevante texto legal pátrio, em face, entre outros motivos, da atuação de grupos de pressão, alega-se que a Lei no 6.404/76 já foi, em grande medida, passada a limpo pela doutrina e jurisprudência dos tribunais. Assim, tem-se indagado, com absoluta (") A segunda parte deste artigo será publicada no próximo número e tem como título "A harmonização juridica entre os países
integrantes da Comunidade Européia e do EFTA".

Revista da Faculdade de Direito da UFRGS, v. 13, 1997
1. Trabalho apresentado no curso de pós-graduaçăo da Faculdade de Direito da Universidade de São Paulo, na disciplina "Sociedades Mercantis no Direito Comparado Il: Sociedades por Quotas de Responsabilidade Limitada e Sociedade por Açöes". 
propriedade, sobre a existência de justificativas plausíveis que autorizariam a mencionada revisão do diploma, notadamente no que tange à relação existente entre os fins visados e os respectivos fundamentos.

Com relação a este tópico, nota-se que muitos dos defeitos atribuídos ao texto não dizem respeito, em grande parte, ao seu conteúdo, mas a sua má aplicação, pelo que melhores resultados poderiam ser alcançados sem qualquer alteração substancial da lei em pauta. Neste sentido, por exemplo, as críticas relativas à dificuldade de compreensão e aplicação do diploma pelo Poder Judiciário, seja em razão de sua especificidade técnica, ou mesmo da urgência em se solucionar determinados problemas societários em um mundo cada vez mais dinâmico, poderiam ser superadas, em parte, com a implementação de um sofisticado sistema de arbitragem, que a recente Lei $\mathrm{n}^{\mathrm{o}}$ 9.307/96 deve propiciar.

Outrossim, se o que se busca é o estímulo ao desenvolvimento do mercado de valores mobiliários, qualquer proposta de lei, para apresentar resultados concretos e satisfatórios, deverá voltar-se para medidas que reforcem a credibilidade dos potenciais investidores no aludido mercado - hoje tão debilitada -, o que não se obtém, à evidência, pela análise das companhias como entes isolados de um universo mais amplo.

Por outro lado, nota-se que mesmo aqueles que admitem a necessidade de uma revisão discutem sobre o exato alcance que

tal expediente deve observar. Neste particular, alguns sustentam a necessidade de uma ampla reforma, mediante a edição de um novo e único diploma, que deveria apenas aprimorar alguns dispositivos, conservando os preceitos da lei anterior que não exijam modificações, como medida de preservação da identidade e coerência do sistema ${ }^{2}$, enquanto outros sustentam a conveniência da reforma parcial da lei, por intermédio de pequenas e sucessivas alterações, o que permitiria uma adaptação constante, gradual e menos traumática do texto, tal como é observado em outros tradicionais diplomas de nosso ordenamento jurídico ${ }^{3}$.

Em que pesem as posições doutrinárias divergentes, observa-se que três relevantes projetos de lei foram apresentados com o escopo de alterar a Lei das Sociedades Anônimas, quais sejam: um amplo projeto de revisão proposto pela Comissão de Valores Mobiliários (CVM), que busca substituir, por completo, a lei vigente, e dois projetos menores, que visam à alteração de tópicos específicos da Lei $\mathrm{n}$ o $6.404 / 76$, sendo que um foi igualmente elaborado no âmbito da CVM, ao passo que o outro é de autoria do Deputado Federal ANTÔNIO KANDIR.

O primeiro projeto, como destacado, busca disciplinar totalmente a matéria, mediante o aproveitamento de determinados dispositivos da Lei no 6.404/76, que são complementados por algumas inovações,

\footnotetext{
2. Ci. JOSÉ LUIZ BULHÕES PEDREIRA, "A Revisão da Lei das Sociedades Anônimas", in Sociedades Anônimas - I Ciclo de Conferências para Magistrados, obra coletiva, EMERJ/IBCB, 1993, págs. 163 e seguintes.
}

3. Cf. CÂNDIDO RANGEL DINAMARCO, A Reforma do Código de Processo Civil, Malheiros, 1995, págs. 28/30. como é o caso da modificação das relações entre os auditores independentes e os acionistas (art. 122, X e $\S 3$ ) e a nova disciplina do acordo de acionistas (art. 118). No entanto, em razão da resistência quanto a determinadas modificações, bem como da extensão do projeto, o mesmo encontra-se praticamente paralisado.

O segundo projeto mencionado, por sua vez, busca a reformulação dos capítulos que tratam das demonstrações financeiras e contábeis, seguindo as diretrizes e padrões contábeis que são atualmente adotados no plano mundial, o que guarda correspondência com o processo de globalização em curso.

Já o Projeto de Lei nº 1.564/96, apresentado pelo Deputado ANTÔNIO KANDIR, conforme dispõe a própria exposição de motivos, visa a ajustar a Lei das Sociedades Anônimas a um novo cenário.

Como explicitado no Projeto, referida lei teria sido editada em um panorama marcado por uma economia fechada, onde o Estado era o grande financiador das empresas, mediante a instituição de incentivos fiscais ou a obtenção de recursos junto às instituições financeiras estrangeiras, o que não mais se verifica no plano concreto. Por conseguinte, as mudanças propostas voltam-se para o mesmo objetivo inicial da Lei $\mathrm{n}^{\mathrm{o}} 6.404$, consistente no fomento do mercado de capitais, mas em um ambiente diverso, marcado pela globalização, pela concorrência acirrada, pela necessidade de privatização - que em algumas passagens do projeto é tratada, incorretamente, como desestatização - e, ainda, pela capitalização das empresas, sem a dependência de recursos estrangeiros.

Essas metas seriam alcançadas mediante o estabelecimento de um equilíbrio entre os interesses dos acionistas controladores e dos minoritários, tal como foi feito, em particular, no direito norte-americano. Sob este prisma, um dos pontos-chaves do projeto é a reformulação do direito de recesso - que será o objeto de análise do presente estudo - e outras medidas paralelas, das quais a mais importante é a revogação da obrigatoriedade de oferta pública por ocasião da alienação do controle ${ }^{4}$.

Ocorre que as propostas apresentadas, por representarem restrições aos direito de acionistas minoritários, têm gerado alguns sérios questionamentos, pelo que merecem uma investigação mais profunda.

\section{0 direito de recesso na lei no 6.404/76 e as modificações promovidas pela lei no $7.958 / 89$}

O direito de recesso, como é cediço, foi introduzido no ordenamento jurídico brasileiro pelo Decreto $\mathrm{n} \mathbf{0} 3.708 / 19$, tendo

4. Esta medida já era proposta por JOSÉ LUIZ BULHÕES PEDREIRA (in "A Revisão da Lei das Sociedades Anônimas", ob. cit., pág. 171). Sobre a conveniência ou não da mudança, confrontem-se as justificativas da proposta com os posicionamentos pág. 171). Sobre a conveniencia ou náo da mudança, confrontem-se as justificativas da proposta com os posicionamentos doutrinários de FABIO KONDER COMPARATO (O Poder de Controle na Sociedade Anónima, RT, 1977), MAURO RODRIGUES PENTEADO ("Apontamentos sobre a Alienação do Controle de Companhias Abertas", in Revista de Direito Mercantil no 76, 1989,
págs. 15 e seguintes) e GUILHERME DORING CUNHA PEREIRA (Alienação do Poder de Controle Acionário, Saraiva, 1995,
págs. 211 e seguintes). págs. 211 e seguintes). 
sido posteriormente incorporado pelas regras aplicáveis às companhias, em 1932.

Embora muito se tenha discutido sobre a natureza e os fins visados, entende-se que o mesmo não visa a favorecer os sócios minoritários ou a própria empresa. Nas palavras de RAQUEL SZTAJN, o recesso é um mecanismo neutro, "voltado para a realidade societária, que permite a cada membro, dentro do jogo de interesses internos, garantir sua liberdade de permanecer ou não associado, sem recorrer à dissolução da sociedade" ${ }^{\text {. }}$.

A particularidade do instituto, no tocante às sociedades anônimas, é que, em razão da dicotomia administrador/investidor, que para RALF DAHRENDORF, inclusive, foi um dos motivos do malogro das idéias marxistas, o interesse tutelado, na situação particular, é o do capitalista, e não o do empresário ${ }^{6}$, o que desloca o enfoque do problema, quando da sua disciplina jurídica.

No caso específico da Lei n⿳⺈ $6.404 /$ 76 , constata-se que o diploma, embora não tivesse por finalidade precípua a tutela dos acionistas minoritários, mas o desenvolvimento do mercado de capitais, ampliou o elenco dos fatos que autorizam o recesso. Neste sentido, o diploma veio a consagrar tal direito nas hipóteses elencadas no art. $137^{7}$, que a doutrina entende como sendo

numerus clausus. Assim, foram contempladas todas as matérias sujeitas à aprovação por quorum qualificado, nos termos em que previstos no art. 136, exceto a criação de partes beneficiárias.

Por força das diretrizes fixadas, ao acionista restou assegurado permanecer na sociedade apenas se mantidas as mesmas prerrogativas existentes no momento de seu ingresso ${ }^{8}$.

No entanto, com o advento da Lei n 0 7.958, de 20 de dezembro de 1989 conferiu-se ao direito de recesso uma nova disciplina jurídica, suprimindo-se a possibilidade de o acionista dissidente retirar-se da sociedade nos casos de deliberações majoritárias que tenham autorizado a "incorporação da companhia em outra, sua fusão ou cisão" (inciso VI) ou a "participação em grupo de sociedade" (inciso VIII). O intuito de tais alterações, nos termos vertentes da exposição de motivos do Projeto de Lei do Senado no $182 / 89$, decorre do fato que "tais providências, quando decididas pelos sócios, são salutares e benéficas para o desenvolvimento dos negócios sociais, não justificando, sobretudo na incorporação ou fusão, a retirada do dissidente através do processo desgastante da apuração do patrimônio líquido, muitas vezes usado abusivamente para, através da criação de embaraços, obter-se vantagens indevidas".

5. "O direito de recesso nas sociedades comerciais", in Revista Mercantil n² 71, 1988, pág. 53.

6. Cf. FÁBIO KONDER COMPARATO, ob. cit., pág. 240.

7. Além destas situaçōes, EGBERTO LACERDA TEIXEIRA e JOSÉ ALEXANDRE TAVARES GUERREIRO acrescentam as hipóte-

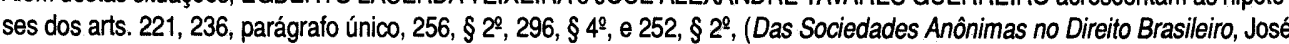
Bushatsky, 1979, vol. 1, pág. 285).

8. Ct. ANTÔNIO JESUS MARÇAL ROMEIRO BCHARA, Comentários à lei das sociedades por açöes, obra coletiva, Resenha Tributária, 1986, vol. 5, pág. 337.

9. Apud ALFREDO LAMY FILHO, A Lei das S.A., co-autoria com JOSÉ LUIZ BULHÕES PEDREIRA, Renovar, 1996, vol. II, pág. 349.

Revista da Faculdade de Direito da UFRGS, v. 13, 1997
O próprio Senador EDISON LOBÃO, autor do projeto em tela, deixou registrado que tinha por escopo "defender a agilidade das sociedades anônimas e evitar que os pequenos acionistas embaracem a vida dinâmica das empresas".

Como não poderia deixar de ser, as modificações promovidas pelo diploma legal geraram imensa celeuma, à época, agravadas pela alegação de casuísmo, em razão da denúncia de que a alteração legislativa visaria a beneficiar determinadas empresas, e do trâmite do Projeto de Lei, extremamente discreto, considerando-se a importância de seu conteúdo.

As repercussões não ficaram restritas ao meio empresarial, chegando a atingir o próprio senador maranhense, que procurou retratar-se em artigo publicado no jornal Folha de S. Paulo; o Consultor da República, que manifestou a sua indignação à inovação verificada; e até mesmo o Presidente da República, que alegou ter sancionado o projeto imbuído de boa-fé ${ }^{10}$.

Ainda que perfunctoriamente, é importante relembrar o debate que tal alteração legislativa gerou, posto que o tópico é objeto de referência expressa do Projeto de Lei $\mathrm{n}$ ㅇ $1.564 / 96$, além do substitutivo apresentado ao mesmo prever expressamente a revogação da mencionada Lei $\mathrm{n}^{\mathrm{o}} 7.958 / 89$.

No âmbito doutrinário, tão logo o Projeto de Lei do Senado n⿳ $182 / 89$ foi aprovado, diversos juristas levantaram-se contra a mencionada alteração legal, salientando que se tratava de evidente retrocesso, efetuado em desacordo com as tendências de proteção dos acionistas minoritários existentes no plano mundial. Visando a essa comprovação, diversos argumentos foram apresentados.

Alegou-se, em primeiro lugar, que $o$ direito de recesso é uma modalidade de direito individual, inderrogável até mesmo por lei expressa.

A base deste entendimento estaria no art. 109 da Lei $\mathrm{n}^{\circ}$ 6.404/76, que estabelece como direitos intangíveis dos acionistas: a) o direito de participar dos lucros; b) o direito de participar no acervo da empresa, em caso de liquidação; c) direito de fiscalização da gestão dos negócios; d) o direito de preferência, em determinadas circunstâncias; e e) o direito de recesso nos casos previstos em lei

Ocorre que, como bem destacou JORGE LOBO, apenas os três primeiros direitos mencionados "não podem ser modificados ou suprimidos por lei expressa, pois decorrem da própria natureza das sociedades de fins econômicos e lucrativos"11.

No tocante ao direito de recesso, porém, tal interpretação não se aplica, seja pelo conteúdo inerente ao direito em pauta, como também pelo fato de o próprio inciso V do art. 109 condicionar o seu exercício a expressa e prévia previsão legal.

10. As suspeitas e particularidades da aprovação do diploma são analisadas em detalhes por MAURO RODRIGUES PENTEADO no estudo "A Lei 7.958/89 e a pretensa modificação do direito de retirada dos acionistas: uma discussão inócua", Revista de Direito Mercantil $n^{2} 77, \mathrm{RT}, 1990$, págs. 30 e seguintes.

11. Direito de retirada nos casos de fusão, incorporação, cisão e participação em grupos de sociedades, Revista dos Tribunais n² 664,1991 , pág. 46. 
Sustentou-se, outrossim, que o'direito de recesso, nas hipóteses fáticas previstas, consistiria em um direito adquirido.

Esse posicionamento também mostrou-se frágil, pois somente há direito adquirido quando alguém incorpora algo ao seu patrimônio - econômico ou moral antes de entrar em vigor a lei nova, o que não se deu no caso concreto. Para alguns doutrinadores, ter-se-ia, quando muito, uma expectativa de direito, que não veio a se concretizar em razão da não-ocorrência do fato deflagrador do mesmo. Assim sendo, não estaria essa hipótese protegida pelo ordenamento jurídico ${ }^{12}$.

Já como terceiro argumento, destacou-se que, em virtude de a mencionada Lei no 7.958/89 não ter revogado expressamente os artigos 225 , IV, 230 e 270 da Lei $\mathrm{n}^{\mathrm{0}} 6.404 / 76$, que igualmente versam sobre o direito de recesso, as situações previstas nos incisos VI e VIII do art. 136 continuariam em vigor.

Esta corrente sustenta que, em face da existência de outras previsões na Lei das Sociedades Anônimas que versam sobre o tópico e não foram derrogadas, a matéria continuaria a receber o mesmo tratamento legal até então existente, embora a intenção do legislador fosse conhecida e inequivocamente distinta.

Entre os diversos estudiosos que se manifestaram neste sentido, pode-se des-

12. Para ARNOLD WALD, "a simples expectativa năo autoriza nem mesmo a prática de atos conservatórios, constituindo mera esperança" (Curso de Direito Civil Brasileiro, RT, vol. 1, 1987, pág. 165)

13. Ob. cit., págs. 30 e seguintes.

14. "Sociedade por Açōes - Incorporação, Fusão e Cisāo - Direito de Retirada", in Revista de Direito Mercantil ne 82, RT, 1991, pág. 54 .

15. "A Lei $n^{9} 7.958$, de 20.12.89, $\mathrm{e}$ o direito de retirada dos acionistas dissidentes", in Revista de Direito Mercantil, $n^{9} 96$

16. Ob. cit., págs. 352 e seguintes.

tacar o trabalho pioneiro de MAURO RODRIGUES PENTEADO ${ }^{13}$, que foi seguido por RUBENS APPROBATO MA$\mathrm{CHADO}^{14}$ e MODESTO CARVALHOSA ${ }^{15}$.

Embora o entendimento dos ilustres juristas seja não apenas coerente como também louvável, considerando-se o direito que buscam resguardar, releva destacar que parcela da doutrina terminou por acatar orientação diversa, sustentando que, embora indesejáveis e eventualmente injustas, as determinações vertentes da Lei $\mathrm{n}^{\underline{0}}$ 7.958/ 89 são inatacáveis

A orientação contrária demonstra que, além de ser conhecida a real intenção do legislador (mens legistoris), os mencionados preceitos da Lei no 6.404/76 que não foram derrogados (arts. 225, 230 e 270) são disposições secundárias e acessórias do art. 137. Dessa forma, seguindo-se a melhor técnica de hermenêutica, e em consonância com o disposto no art. 2o da Lei de Introdução ao Código Civil, tem-se que a alteração do principal implica a correspondente alteração do dependente. Outrossim, o art. $3^{\circ}$ da Lei $\mathrm{n}^{\mathrm{o}} 7.858 / 89$, observando orientação rotineira, revogou expressamente as disposições em contrário.

Entre os adeptos dessa linha de argumentação encontram-se JOSÉ LUIZ gumentação encontram-se JOSE LUIZ

Revista da Faculdade de Direito da UFRGS, v. 13, 1997
LOBO ${ }^{17}$, JOAQUIM ANTÔNIO PENALVA SANTOS ${ }^{18}$, ALFREDO LAMY FILHO ${ }^{19}$ e WALDIRIO BULGARELLI ${ }^{20}$.

No plano jurisprudencial, esse impasse ainda persiste, existindo decisões favoráveis tanto à primeira linha de argumentação ${ }^{21}$, que sustenta a não-derrogação da Lei $\mathrm{n}^{\mathrm{O}}$ 6.404/76 pela Lei $\mathrm{n}^{\mathrm{O}}$ 7.958/89, como à segunda ${ }^{22}$.

\section{A disciplina do direito de recesso no projeto de lei $n^{0}$ $1.564 / 96$}

O fato, porém, é que o Projeto apre sentado pelo Deputado KANDIR vai de encontro à Lei Lobão, destacando-a como um dos motivos a exigir reparos na Lei das Sociedades Anônimas.

Como conta da justificativa do Projeto, essa discussão sobre a efetividade da Lei Lobão terminou por gerar um duplo dilema: deixou os acionistas minoritários completamente sem respaldo, ao mesmo tempo que não assegurou aos majoritários uma posição confortável para fazer as mudanças necessárias. Por tais motivos, o Projeto visa a reintroduzir o direito de retirada, mas de forma diversa do que figurava no texto original da lei.

17. Ob. cit., pág. 49

18. "Incorporaçāo, fusão e cisão - Protocolo - Ato de acesso", in Sociedades Anônimas - I Ciclo de Conferências para Magistrados, ob. cit., pág. 124.

19. Ob. cit., pág. 352

20. Fusőes, incorporaçöes e cisöes de sociedades, Atlas, 1996, pág. 237.

21. Ct. Decisão do Tribunal de Alçada de Minas Gerais, avaliada por PAULO SALVADOR FRONTINI, in Revista de Direito Mercantil $n^{2} 86$, págs. 74 e seguintes.

22. A matéria foi apreciada pela $1^{3}$ Câmara Cível do Tribunal de Justiça do Paraná (Apelaçăo Cível $n^{2} 44.249$, Rel. Des. OSIRIS FONTOURA).
Apreciando-se a matéria de forma articulada, pode-se apontar as seguintes propostas: renumerando-os e subdividindo-os, salvo o disposto no inciso IV, no qual passa a ser exigido quorum qualificado não mais para alterar o dividendo obrigatório, mas para reduzi-lo.

Já o $§ 1^{\text {O }}$ do preceito é alterado para fazer constar que a validade de deliberações que afetem as ações preferenciais depende de ratificação ou aprovação dos acionistas minoritários efetivamente prejudicados. Outrossim, é fixado o prazo de um ano para que qualquer providência seja tomada neste sentido.

b) A segunda alteração alcança diretamente o art. 137 da Lei, estabelecendo:

a. nos casos dos incisos I e II do art. 136 , somente terá direito de recesso o titular de ações de espécies ou classes prejudicadas;

b. é restaurado o direito de recesso na hipótese de participação em grupo de sociedades;

c. restringe-se o direito de recesso, ao eliminar expressamente os casos de ci- a) alteração do art. 136 da Lei, 
são (o que já havia sido efetuado pela Lei Lobão), dissolução ou cessação do estado de liquidação, sendo apresentadas como justificativas:

- quanto à cisão, segundo o que dispõe o Projeto, o acionista passa a permanecer com a mesma participação acionária que tinha na empresa cindida, ao contrário do que se dá nos casos de incorporação e fusão. Este aspecto implica as alterações dos arts. 223 (cisões de companhias abertas devem gerar necessariamente companhias abertas) e $230, \S 5^{\circ}$.

Nesta passagem, nota-se que a proposta afasta-se do modelo americano, que é citado como referência no Projeto, na medida em que confere tratamento diferenciado para a cisão e a incorporação, além, evidentemente, da exclusão do direito de recesso ${ }^{23}$;

- quanto à dissolução, porque o pagamento dos reembolsos é a decorrência natural do processo;

- quanto à cessação do estado de liquidação, porque não há fundamento econômico que o justifique ${ }^{24}$;

d) propõe o direito de retirada nos casos de fusão e incorporação, mas somente para acionista de a) companhias fechadas; b) empresas abertas com ações não negociadas em bolsa ou no mercado organizado; e c) empresas abertas cujas ações

23. Para uma análise mais minuciosa do assunto, vide estudo de MAURO BRANDÃO LOPES ( $A$ cisão no direito societário, RT, 1980, págs. 238 e seguintes).

24. A matéria é enfocada, entre outros, por MAURO RODRIGUES PENTEADO, in "Dissolução e liquidação de sociedades", Brasília Jurídica, 1995.

25. Corporate Law, Boston; Little, Brown and Company, 1996, págs. 443 e seguintes.

não tenham liquidez nestes mercados, segundo critérios que seriam fixados pela CVM.

A orientação adotada tem como pressuposto a noção de que a fusão e a incorporação pouco afetam as companhias com ações de liquidez em bolsa de valores e mercado de balcão, onde os acionistas podem negociá-las, caso entendam que os aludidos procedimentos são contrários aos seus interesses. Segundo o autor do Projeto, o que se busca é definir os limites e condições para o exercício do direito de recesso, mas sem criar obstáculos a processos de "reorganização societária" que se façam necessários.

No entanto, embora referido procedimento ampare-se na experiência estrangeira, a sua aplicação no diteito pátrio é temerária.

No tocante ao modelo americano, que é citado como referência no Projeto, ensina o Prof. ROBERT CHARLES CLARK, da prestigiada Universidade de Harvard, que o direito de recesso está tradicionalmente associado, de um lado, às operações de fusão, ou mesmo à venda ou transferência de parte substancial dos ativos das empresas, em dissonância com o curso normal dos negócios, ou, então, às alterações do estatuto social que afetem os direitos de acionistas minoritários ${ }^{25}$.

Revista da Faculdade de Direito da UFRGS, v. 13, 1997
As regras aplicáveis variam segundo as diversas jurisdições, mas normalmente é exigido que o acionista dissidente tenha votado contra a operação questionada, demonstrando a sua contrariedade para com a deliberação majoritária. Nesta hipótese, aguarda-se a oferta de um preço justo pela sua participação acionária, que, não ocorrendo, fatalmente leva à discussão em juízo do referido valor.

Como estes processos são morosos e caros, as previsões legais mais recentes têm estabelecido a obrigatoriedade de a empresa pagar de imediato o montante que entende devido, apresentando as informações que serviram de substrato para a valoraçãa ${ }^{26}$.

Como justificativa para a existência deste direito, porém, são apresentados dois argumentos relevantes.

Em primeiro lugar, se um indivíduo compra ações de uma empresa, espera-se que ele permaneça vinculado àquele empreendimento específico. Isto é, não se pode obri$\operatorname{gar}^{27}$ que um acionista que adquiriu ações de uma editora seja surpreendido por uma mudança radical dos acionistas majoritários, que decidem transformá-la em uma empresa de exploração agropecuária (defeated expectations argument). Neste contexto, o direito de recesso permite a continuidade de determinados empreendimentos, em consonância com a deliberação majoritária, mas ressalva os interesses daqueles que não pretendem e/ ou pretendiam realizar determinados investimentos.

Por outro lado, algumas operações específicas, como é o caso da fusão, envolvem determinados riscos, que são inerentes às mesmas, nos quais os minoritários tendem a receber um tratamento desigual. Neste particular, o direito de recesso emerge como uma solução intermediária, a título de contraprestação.

Contra o direito de recesso, todavia, além de dois argumentos tradicionais ${ }^{28}$, é citado o modelo ora adotado pelo Projeto (stock market exception).

Com efeito, vinte e três estados americanos adotam o sistema que proíbe o direito de recesso quando as ações dos acionistas minoritários podem ser negociadas livremente no mercado de valores mobiliários. Esta teoria, a rigor, ampara-se no fundamento de que o direito de recesso é desnecessário quando existe um mercado de valores mobiliários aberto.

No entanto, existe um forte movimento contrário a esta orientação, com base no argumento de que este procedimento, mesmo nos Estados Unidos, não permite aos minoritários obter um preço justo pelas suas ações, posto que o valor que o mercado de ações oferece, além de poder ser manipulado, baseia-se em outras referências (v. $g$.

26. STANLEY SIEGEL, Corporations and other Bussiness Organizations, in "Fundamentals of American Law", obra coletiva, New York University School of Law, 1996, pág. 363.

27. No direito brasileiro, esta orientaçăo emana, inclusive, de dispositivo constitucional (art. $5^{\circ}, \mathrm{XX}$ ).

28. Alegam-se que (1) existem outras operaçōes de riscos, além daquelas habitualmente admitidas pelos tribunais, que não geram direito de recesso, devendo-se salientar, ainda, os (2) efeitos negativos decorrentes dos pagamentos efetuados, às vezes até de forma abusiva, aos minoritários (cash drain argument). 
informaçōes disponíveis sobre as empresas), que não o próprio patrimônio da empresa. Em outras palavras, o mercado de valores mobiliários não é sensível, e por conseguinte não reflete, necessariamente, a diferença que pode existir entre o preço e o valor da ações.

Tanto é, que esta exceção foi eliminada do Model Bussiness Corporation Act, de 1978, diante da constatação de que, nestas hipóteses, notadamente no período de 1974/1975, várias companhias aproveitaram-se da queda verificada nos preços dos valores mobiliários e compraram em bolsa suas próprias ações de acionistas minoritários ${ }^{29}$.

Daí, alegar-se que este sistema é inconsistente com a real função do direito de recesso, a manutenção de uma reserva de valor (reservation price), notadamente quan-

do determinadas operações visam justamente à eliminação de acionistas minoritários ${ }^{30}$

No caso do Brasil, em particular, as dúvidas sobre a correta aplicação dos preceitos são ainda mais consistentes, na medida em que nosso mercado de valores mobiliários ainda se mostra extremamente vulnerável às manipulações de especuladores.

Ante o exposto, é forçoso concluir que a transposição de institutos alienígenas para o ordenamento jurídico brasileiro, embora tenha sido um expediente adotado pela própria Lei $\mathrm{n}^{\circ} 6.404 / 76$, com algum sucesso, não deve iludir os responsáveis, ante a defasagem existente entre a realida de que assola o mercado de capitais no Brasil e outros mais estruturados. No entanto, se as propostas apresentadas, caso sejam acolhidas, vão solucionar os problemas existentes, só a experiência dirá

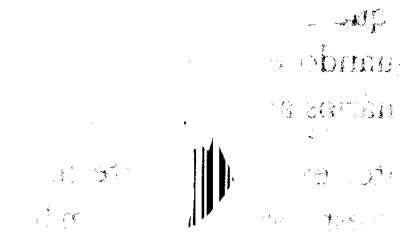

\section{Cf. FRANK H. EASTERBROOK e DANIEL R. FISCHEL, The Economic Structure of Corporate Law, Boston, Harvard University} Press, 1996, pág. 149.

30. A respeito do tema, confira-se, ainda, os estudos do Prof. DETLEV F. VAGTS (Basic Corporation Law, The Foundation Press, New York, 1989, págs. 742/750), da Universidade de Harvard, e do Prof. ROBERTW. HAMILTON (Corporations, West Publishings, St. Paul, 1994, págs. 548/557), da Universidade do Texas.

\section{LA SALLE}

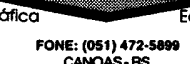

